\section{Legal protection}

\author{
Susan E. Foden
}

Patent Strategy for Researchers and Research Managers. By $H$. Jackson Knight. Wiley: 1996. Pp. 166. £32.50.

THE aim of this book is to encourage the "technical professional" to think strategically about filing patent applications and building patent portfolios. The author not only describes the basic concepts of intellectual property and patent procedure, but also considers the human elements of the process - the driving force behind invention and the personal interactions between researchers, managers and patent agents at various stages of the research process.

The first chapter provides a sound introduction to patent law, the workings of patent offices and requirements for obtaining a patent. Particularly informative are the sections on types of patents and on the parts of a patent. In the latter, the author clearly explains the various reference criteria for patent documentation - important information often overlooked in other texts on preparing a patent proposal.

The value of a patent lies mainly in the scope of exclusivity that the owner may hope to secure. In outlining several easyto-follow models of how this may be best achieved, the author begins to put the whole patenting business into a realistic perspective in terms of its value and exploitation. The passing references to licensing seem out of place, however: licensing and licensing strategy are enormous topics in their own right, and it is impossible to do justice to them without looking more widely at the area of exploitation opportunities. Indeed, both here and elsewhere in the book, it is not clear what area of science the author is talking about, or to whom he is talking. The relevance of his points often depends on whether the reader is a private inventor, a university researcher, a start-up company manager or an employee of a large international corporation. The author's background is the last of these, and on the whole he seems to be writing with this environment in mind. Those whose experience is mainly with inventions arising in the academic sector and in areas of rapidly moving and highly competitive biomedical research will find the book less useful.

But the real meat of the book is the thorough, well-presented third chapter on developing a patent strategy. The author guides us through fundamental thinking that could well apply in a variety of circumstances. He deals with the military principles behind strategic thinking and goes on to the development of a patent strategy model. Several summary tables offer useful checklists or reminders for later reference.

After exposure to the strategic thinking mode, the following chapter on global filings reads like a harsh return to the facts and practicalities introduced earlier in the book. My own preference would have been to proceed directly to the next chapter, "Researching with Intellectual Property in Mind", on the human elements of the process. The author starts with debatable statement: "Researchers, as a whole, are not thought of as inventors". Nevertheless, it is interesting to be taken through the more reflective aspects of inventive philosophy and to look at the environments and management styles that may encourage - or discourage - the process. There naturally follows a chapter that looks in some detail at the relationships between inventors, patent attorneys, patent agents and patent liaison officers.

Thereafter the book tends to lose its way, dealing as it does with disclosure and filing decisions and the responsibilities of the researcher after the filing. Repetition here of earlier material on the patent process and procedures makes for somewhat dreary reading. And far from being given succinct or comforting conclusions, the reader is left dangling among nonstrategic issues such as maintenance fees and prosecution decisions.

Overall, the book offers a readable description of the patent process and a solid approach to the issues of filing and strategy. But do bear in mind that it is biased towards nonbiological research in a company environment.

Susan E. Foden is at Cancer Research Campaign Technology Ltd, Cambridge House, 6-10 Cambridge Terrace, Regent's Park, London NW1 4JL, UK.

\section{New Journals}

This year, Nature's annual New Journals review supplement will appear in the issue of 5 September. Publishers and learned societies are invited to submit journals for review as well as details of any eligible electronic journals. Journals that first appeared during or after June 1994 and issued at least four separate numbers by the end of May 1996 will be considered. Frequency of publication must be at least three times a year and the main language used must be English. Deadline for submission is 14 June.

When submitting journals for review, please send at least four different issues (the first, the most recent and any two others) of each title, together with full details of subscription rates. For further information please contact Peter Tallack, Nature, Macmillan Magazines Ltd, Porters South, Crinan Street, London N1 9XW, UK. Tel: +44 (0)171 843 4567; e-mail p.tallack @nature.com.
Delicate investigations

Stephen Mason

Lines of Light: The Sources of Dispersive Spectroscopy, 1800-1930. By John C. D. Brand. Gordon and Breach: 1995. Pp. 266. £84, $\$ 140$ (hbk); £36, $\$ 60$ (pbk).

FOR Faraday, light constituted "a most delicate investigator of molecular condition". In Lines of Light, the distinguished spectroscopist John Brand relates how Faraday's perception was realized historically in the development of optical spectroscopy. The book covers instrumental innovations, theoretical interpretations and chemical and astrophysical applications, from the time of Fraunhofer (1787-1826) to the symbiotic growth of quantum mechanics and spectroscopy during the decades between the two world wars, before the advent of the laser.

Each of the 12 chapters deals with a particular topic and period and ends with brief summaries of the lives of the principal workers. After providing a general introduction to physical theory during the nineteenth century, the author begins with the transverse-wave theory of light and the extension of the known spectrum to the infrared and ultraviolet ranges. $\mathrm{He}$ gives an account of the evolution of methods and standards of wavelength measurement and describes emission and absorption studies, including laboratory and stellar spectrum analysis. Following a description of pioneering infrared spectroscopy and matter-radiation equilibrium problems, the author discusses the mapping and analysis of atomic spectral series and the molecular spectra of gases, leading on to the empirical generalizations and early quantum interpretations. He ends with the salient discoveries of atomic and molecular electron orbitals, the Raman effect, the Franck-Condon principle, and electron and nuclear spin - all part of the convergence of theory and experiment that resulted in the alliance of spectroscopy and quantum mechanics.

Some 36 illustrations add to the clarity of the text. As the first substantial history of spectroscopy, this book will appeal to both students and historians of physical science.

Stephen Mason, emeritus professor of chemistry at the University of London, is at 12 Hills Avenue, Cambridge CB1 4XA, UK.

Correction. In Patrick Naylor's review of Pattern Recognition and Neural Networks by B. D. Ripley (Nature 381, 206; 1996), the publisher was incorrectly given as MIT Press, instead of Cambridge University Press. Our apologies. 